\title{
Chemistry, Paradigms, and a View of Epistemic Pluralism: To the Issue of the Nature of Disagreements in Philosophy and in Science
}

\author{
Posthumous paper of Rein Vihalemm prepared to be presented at the $15^{\text {th }}$ \\ Congress of Logic, Methodology and Philosophy of Science, 3-8 August, \\ Helsinki, Finland.
}

First of all, I would like to say that perhaps my paper would have found a more appropriate place in the section of General Philosophy of Science, or Historical Aspects in the Philosophy of Science of this conference. I am disappointed that there is no separate session for the philosophy of chemistry at this congress, as it was at the previous congress in 2011 in Nancy. As you can see, the title of my discussion mentions chemistry. Although I do not intend to talk about the specific problems of the philosophy of chemistry, I would still like to emphasize that chemistry, especially its historical practice, has attracted more and more attention in the philosophy of science in recent decades, influencing the turn from the vision of science as a timeless logic-centred system of statements towards the history- and practice-centred approach.

One of the issues that has become a popular topic in that context is the problem of pluralism in science. Hasok Chang's 'active normative epistemic pluralism' manifested in his "water book", pursuing integrated study of history and philosophy of science (Chang, 2012a), has provoked quite a widespread debate. Chang's work has been welcomed as a very interesting and highly stimulating one, among other things in the sense that the author's conception provokes disagreements with him, encouraged by his positive attitude to disagreements everywhere.

Chang emphasizes that "not unlike modern philosophy, [science as well] ... thrived on disagreement, dispute and debate. [...] In all situations that we recognize as scientific at all, there are disagreements among scientists but also sufficient common ground to allow productive debates; it is a matter of degree, how deep the disagreements go" (Chang, 2012a, p. 107).

This goes together with his pluralism in philosophy and in science. It provides a good opportunity to discuss the topical issue of the nature of disagreements as 
there have been differences that have been pointed out among disagreements in different domains in the disagreement literature (Kornblith, 2010). It has been noticed that in mathematics, logic and science, consensus is established more clearly than in philosophy, and in the humanities in general, where it remains largely unachievable; in philosophy there is no "long-standing progress" and therefore "epistemic modesty" seems to be "the only rational position available" (Kornblith, 2010, p. 52). However, this conclusion is derived in the context of traditional logic-centred epistemological view of science, according to which in science disagreements do not pose a problem, a consensus is reached there simply because science is a system of statements which is objectively, logicallymathematically, or empirically self- correcting. The aim of this paper is to consider the different nature of disagreements in science and in philosophy in the context of the history- and practice-centred approach proceeding from a modified Thomas Kuhn's paradigm-conception of science and scientific revolutions.

The analysis is focused on the critique of the received view of the Chemical Revolution which played the central role in Chang's becoming a pluralist about science. Chang admits: "I became a pluralist about science because I could not honestly convince myself that the phlogiston theory was simply wrong-or even genuinely inferior to Lavoisier's oxygen-based chemical theory" (Chang, 2012a, p. 253). Though he emphasizes that this "provocative statement" was there "immediately qualified [...] It is of course true that a striking episode serves as an inspiration, and as some measure of support, for a general position. So, if one wishes to reject normative pluralism in general, it would be in one's interest to dispute my normative claim about the Chemical Revolution and some other similar striking episodes that I have studied" (Chang, 2015, p. 98).

It should be emphasized that to a considerable extent the development of Kuhn's views took place on the basis of case studies from the history of chemistry and it were exactly the phlogiston theory and the Chemical Revolution that played an important role there. Citing Hoyningen-Huene (2008, p. 114): "Kuhn clearly had the chemical revolution in mind when he formulated his theory." The understanding of Kuhn's conception gives rise to disagreements even nowadays and there is no consensus whatsoever as to the perspective of understanding it and developing it further as a practice-based conception. I agree with Joseph Rouse's claim that Thomas Kuhn's bestseller The Structure of Scientific Revolutions has also been perhaps the most misunderstood. In particular, the depth of his criticism of the representationalist epistemology has often been overlooked. Kuhn has most commonly been read by philosophers as someone who ascribes a leading 
role to theory in science, who emphasizes the noncumulative character of theory change, and who denies the possibility of non-neutral criteria for assessing the cognitive worth of such changes. (Rouse, 1987, p. 26). Kuhn's ideas should be developed "further in the direction of an account of science as practice than he himself would be happy with" (Rouse, 1987, p. 27).

Such an evaluation by Rouse still holds. Chang, who is developing a certain practice-based philosophy and history of science, does not concentrate on Kuhn's conception much, although admitting certain similarities with it, but does not develop and rather criticizes it. For many critics of Kuhn's conception of scientific revolution and, especially the Chemical Revolution, the Kuhn's conception being practice-based tends to elude them and the paradigm is seen rather as a theory and thus the traditional statements-centred representationalist epistemological point of view is taken. Even Chang's above-quoted confession"I became a pluralist about science because I could not honestly convince myself that the phlogiston theory was simply wrong-or even genuinely inferior to Lavoisier's oxygen-based chemical theory"-is actually based on him seeing the problematicity of the Chemical Revolution still in the context of theory and evidence (though he says "system" instead of "theory"; Chang, 2012a, p. 12), not as switching from one paradigm - which is an operating system or research matrix, rather than a system of knowledge-to another. One could perhaps say that Chang criticizes the received, theory-centred view of understanding of the Chemical Revolution (the scientific revolution in general) together with the Kuhn's paradigm-conception if construed in the same way. Chang does not deny that there was a revolution, but is against simplistic understanding of it. His explanations, especially concerning methodological incommensurability (in Chang, 2012b and 2015) are quite largely acceptable. However, a better understanding of the issue can be achieved, I think, by developing Kuhn's ideas further in the context of practice-based approach.

Chang argues that the rejection of the phlogistonist system was actually premature, epistemologically not justified and "it would have been better for science if the phlogistonist system had been allowed to continue its work" (Chang, 2012a, p. 1). Was he right? Of course he was right in the sense that the phlogiston theory was definitely not wrong or non-scientific, but the question is whether this paves the way for the criticism of Kuhn's scientific revolutions and Kuhn's conception of science in general? In my opinion, it does not. As a matter of fact I find Chang's approach-namely, he develops philosophy of science that strives toward the integration into the history and practice of science-very 
attractive, but unfortunately it remains so-to-say epistemology-centred in the end, and in my opinion there lies the reason for Chang's taking such a position towards Kuhn's scientific approach and especially his conception of the scientific revolution, that there is enough reason to disagree with him. He does emphasize that science should be understood "in terms of systems of (scientific) practice", but he nevertheless speaks of these as of epistemic activities, purely from the aspect of knowledge, as of the ways of obtaining knowledge, though at the same time not "forgetting that knowledge is rooted in practice" (Chang, 2012a, p. 15). Chang's normative epistemic pluralism, as he calls it, is active scientific realism, which he characterizes as "a commitment to maximize our learning from reality" (Chang, 2012a, p. 220).

He speaks in a very Kuhnian manner about the development of the incommensurable systems of practice, but only in order to obtain as much knowledge as possible. And as it was mentioned already, he finds that the scientific revolutions and the highlighting of the normal science by Kuhn is epistemologically not justified, because this results in unnecessary and premature closure of some practices that actually promise further knowledge, which can on a closer look also be confirmed by the real history.

Indeed, it must be admitted that when we refer solely to the obtaining of the knowledge about the world which is inexhaustible and not only as a whole, but also in no matter how narrow field of research, it is obvious that it would be unwise to assume that any research practice would exhaust itself during a period, that all the possible and scientifically acceptable data about the research object would be obtained, thus requiring this certain research practice to be cast aside and concentrate on a new one, ignoring all other possibilities. The question, however, is whether science is, whether it should be understood only from the aspect of knowledge, the dedication to learn from the reality, simply the maximizing of the obtained knowledge that is described as scientific, the increasing of knowledge which is endless, because the world itself is inexhaustible? It can also be said: epistemic pluralism is indeed justified, however, that does not give rise to the scientific pluralism. For science is characteristic, as Kuhn has shown, progress through revolutions, i.e. through paradigm-changes - whereby the superseding paradigm and superseded one are incommensurable-which ensure significant improvement of puzzle-solving efficiency, i.e. scientific progress. From this point of view a pluralistic science would be terribly inefficient!

But let us come to Kuhn then. One has to agree with Joseph Rouse that Kuhn, whose main work is namely The Structure of Scientific Revolutions, has yet not 
been understood as the critic of the traditional representational epistemology and theory-centred and in general statements-centred and their proof-centred philosophy of science and an important pioneer for the new practice-based approach of science. In this paper I am first and foremost interested in the issue of disagreements in the development of science, which is characterized by the progress through revolutions, that is, paradigm changes, the main scheme of which is the sequence of normal science-crisis—revolution-normal science. The gist of Kuhn's paradigm-centred concept of science lies in the existence of the normal science being the criterion for the so-to-say proper science, it differentiates mature science from philosophy and humanitarian areas in general, also social studies, but also from the pre-paradigm science. It needs to be emphasized-this is something that often remains even unnoticed-that normal science means progress characteristic to science alone. Kuhn explains in the last chapter of his book, 'Progress through Revolutions', that in the frequent debates on whether one area of research is science or not, it is not the issue of the verbal-logical definition of science or scientificity, but rather the following: "Why does my field fail to move ahead in the way that, say, physics does? What changes in technique or method or ideology would enable it to do so?" (Kuhn, 1970, p. 160). Kuhn asks: "Does a field make progress because it is a science, or it is a science because it makes progress?" (Kuhn, 1970, p. 162). And he proceeds from the latter-that is, Kuhn does not define science on the basis of the methodology proceeding from some a priori philosophy and epistemology, but from the notion that science is known as a social-historical phenomenon, an intellectual activity characteristic of a certain human community - the scientific community, the enterprise of research work, which is undoubtedly set to progress and reach new results all the time. And the so-to-say formula of this process is, as it was mentioned already, the following sequence: normal science-crisis—revolution-normal science. Kuhn stresses that science can be differentiated from all other enterprises on the basis of progress as its most salient characteristic:

Viewed from within any single community [...] whether of scientists or nonscientists, the result of successful creative work is progress. How could it possibly be anything else? [...] If we doubt [...] that non-scientific fields make progress, that cannot be because individual schools make none. Rather, it must be because there are always competing schools, each of which constantly questions the very foundations of others. The man who argues that philosophy, for example, has made no progress emphasizes that there are still Aristotelians, not that Aristotelianism has failed to progress. 
These doubts about progress arise, however, in the sciences too. Throughout the pre-paradigm period when there is a multiplicity of competing schools, evidence of progress, except within schools, is very hard to find. [During the pre-paradigm period] individuals practice science, but [...] the results of their enterprise do not add up to science as we know it (Kuhn, 1970, pp. 162-163).

Progress, characterized by paradigmatic science, is a continuous progress based on the revolutions or changes of paradigm in the said formula, that is, normal science-crisis—revolution-normal science; progress does not occur within normal science or one paradigm only; the paradigm change as well that results in a new normal science is not simply a novelty, a new approach or a point of view as it is, say, in humanitarian areas, but necessarily progress, the thing that cannot be observed in other areas. This paradigmatic science as proper science is, indeed, continuously progressing, the nature of scientific communities, as Kuhn writes, "provides a virtual guarantee that both the list of problems solved by science and the precision of individual problem-solutions will grow and grow" (Kuhn, 1970, p. 170).

Kuhn refers to the analogy with the biological evolution, in which he considers especially important the fact that it is not a process of evolution toward anything, but that the natural selection teaches us "to substitute evolution-from-what-wedo-know for evolution-toward-what-we-wish-to-know" (Kuhn, 1970, p. 171). The traditional approach of science refers to the desire to move through the errors towards the truth; to find out what the world is like, to formulate a number of truthful claims, that is, to create a more and more perfect proven and verified theory that describes the world better and better. But as Kuhn emphasizes:

The net result of sequence of such revolutionary selections, separated by periods of normal research, is the wonderfully adapted set of instruments we call modern scientific knowledge. Successive stages in that developmental process are marked by increase in articulation and specialization. And the entire process may have occurred, as we now suppose biological evolution did, without benefit of a set goal, a permanent fixed scientific truth, of which each stage in the development of scientific knowledge is a better exemplar (Kuhn, 1970, pp. 172-173).

The social-historical development where science belongs, cannot, of course be simply biologized, but its certain analogy with the mechanisms of biological evolution must be seen as a starting point for understanding science as a practice, not only as knowledge, understood as a system of statements that pursues to 
describe the world, to represent it as through the God's eye. Science is a specific form of practice in its general context, that is, one way how the social-historical human activities or culture takes place, meaning creating, maintaining and developing the human world in the nature; and practice is the continuation of the biological evolution as the cultural evolution.

When speaking about Kuhn, the most important thing is, as I have emphasized, its being based on practice, which tends to be overlooked, and therefore, as it has been brought out, the paradigm is often identified as theory, and normal science as a development within one theory by considering how that as a system of statements represents the world, connects with facts and evidence. Chang, too, in his criticism of Chemical Revolutions tends to indicate that the phlogiston theory was actually not refuted, that Lavoisier's oxygen theory was not empirically better confirmed. Scientific revolution does actually not take place by the old theory being cast aside as epistemologically defective, as something that, according to come criteria of scientificity, turns out to be excluded in the light of the new theory. It is something else altogether. Namely, in a scientific community the new paradigm gives rise to normal science which is more effective for identifying and solving the scientific problems (Kuhn, as it is known, and it is very important, characterized that as the puzzle-solving tradition). In Kuhn's paradigm, as the disciplinary matrix all four components that form the whole are important:

1) The one that Kuhn calls 'metaphysical paradigms' or 'the metaphysical parts of paradigms', but which should more correctly named 'Scientific World Picture'- the modelled reality;

2) Symbolic generalizations - the schemes of laws of nature;

3) Shared values or methodological principles or norms;

4) Shared examples/exemplars/model-situations or paradigms in the narrower sense of the term.

The fourth component is, in a sense, substantially the most important, but is most often not understood to the necessary extent. Kuhn states in the 'Postscript' of his Structure: "The paradigm as shared example is the central element of what I now take to be most novel and least understood aspect of this book. Exemplars will therefore require more attention than the other sorts of components of the disciplinary matrix" (Kuhn, 1970, p. 187). It is this component that most directly differentiates the paradigm connecting the scientific community from the system of verbal-logical statements or beliefs; the paradigm connecting the scientific community is associated with a cooperative enterprise, where, among 
other things, tacit knowledge and skills are important. According to Kuhn, it is very characteristic of paradigm that an accepted paradigm gives rise to normal science, a successful puzzle-solving tradition, meaning harmony in activities, but not necessarily in beliefs, in formulations of knowledge in statements: "[Scientists] can, that is, agree in their identifications of a paradigm without agreeing on, or even attempting to produce, a full interpretation or rationalization of it" (Kuhn, 1970 , p. 44).

Kuhn does also speak about knowledge and use the word 'consensus'. However, as it was seen above, he speaks about scientific knowledge, when referring to analogy with biological evolution, not bearing in mind the system of statements, but rather, as he says, "the wonderfully adapted set of instruments" as "the net result of sequence of [...] revolutionary selections"; that is, he refers to that very same sequence of paradigms that enables the successful problem-solving activities of a scientific community as normal science. The same applies to 'consensus'. He uses this word, as he later says, in the foreword to the compendium The Essential Tension (Kuhn, 1977), only because he could not find any other more suitable expressions to characterize normal science functioning within the framework of an accepted paradigm, where it has nothing to do with consensus in its common meaning, that is, consensus on the level of the logical-verbal beliefs. This fact was also especially underlined by Rouse, who writes on the paradigm-based consensus:

There is room for considerable disagreements within such a field, often about very basic issues. What is shared, however, is a sense of what is at issue, why it matters, and what must be done to resolve it. Such agreement is not merely compatible with disagreements about specific issues within the field [called by Kuhn a disciplinary matrix]; it is what makes significant disagreement intelligible [...] Scientific communities are characterized by common problems and techniques and by reference to the same achievements, not by monolithic consensus (Rouse, 1987, pp. 31-32).

With Kuhn's concept of science it is important to bear in mind that it does not resemble the inductive generalization of factual history of science, but is a certain idealization obtained by analyzing the history and practice of science that brings out the mechanism of progress characteristic to science in the pure form. As any scientific idealization, it is counterfactual by nature and is both explanatory of the progress of science and normative in its meaning. It allows to show why one does not necessarily agree with many of Kuhn's critics - as the aforementioned Chang or the earlier criticism by Popper or Feyerabend-towards, for instance, 
normal sciences. In an article published quite recently in the Synthese journal, the author Samuel Schindler (2013, p. 4137) calls Kuhn's conception the Kuhnian mode of History and Philosophy of Science (HPS). I agree with this Kubnian mode of HPS: however, I think that this—what Schindler calls "a priori”- account of rationality should be understood rather as an idealization of scientific historical practice, that is, this is the way how this account of rationality "originates [as Schindler admits] in the study of scientific practice". I have tried to investigate science in this way.

It should also be pointed out that the paradigmatic science may not be the ideal in the sense of being epistemologically the best way "to maximize our learning from reality" (Chang, 2012a, p. 220) or the most sophisticated method of "rational discussion ... [i.e.] of stating one's problem clearly and examining its various proposed solutions critically" (Popper, 1968, p. 16), "[in order to] learn something about the riddle of the world in which we live, and the riddle of man's knowledge of that world" (Popper, 1968, p. 23) or "the great human endeavour of trying to make social progress towards an enlightened, wise world" (Maxwell, 2007 , p. 10) or the like. This paper is only meant to show-in the context of the discussion about pluralism and disagreements in science-what is characteristic to science as it actually exists in our era-the era of technology.

\section{References}

Chang, H. (2012a), Is Water H2O?: Evidence, Realism and Pluralism, Boston Studies in the Philosophy of Science, Dordrecht: Springer.

(2012b), 'Incommensurability: Revisiting the Chemical Revolution,' in V. Kindi \& T. Arabatzis (eds.) Kuhn's The Structure of Scientific Revolutions Revisited, London: Routledge, pp. 153-176.

_ (2015), 'The Chemical Revolution revisited,' Studies in History and Philosophy of Science, vol. 49, pp. 91-98. http://dx.doi.org/10.1016/j.shpsa.2014.11.002

Hoyningen-Huene, P. (2008), 'Thomas Kuhn and the chemical revolution,' Foundations of Chemistry, vol. 10, pp. 101-115. http://dx.doi.org/10.1007/s10698-008-9044-7

Kornblith, H. (2010), 'Belief in the Face of Controversy', in R. Feldman \& T. A. Warfield (eds.) Disagreement, New York: Oxford University Press, pp. 29-52. http://dx.doi.org/10.1093/acprof:oso/9780199226078.003.0003

Kuhn, T. (1970), The Structure of Scientific Revolutions, $2^{\text {nd }}$ edition, Chicago: University of Chicago Press.

(1977), The Essential Tension, Chicago: University of Chicago Press. 
Maxwell, N. (2007), 'From knowledge to wisdom: the need for an academic revolution,' in R. Barnett \& N. Maxwell (eds.) Wisdom in the University, New York: Routledge, pp. 1-20. http://dx.doi.org/10.1080/14748460701440350

Popper, K. (1968), The Logic of Scientific Discovery, London \& New York: Routledge.

Rouse, J. (1987), Knowledge and Power: Toward a Political Philosophy of Science, Ithaca: Cornell University Press.

Schindler, S. (2013), 'The Kuhnian mode of HPS,' Synthese, vol. 190, no. 18, pp. 41374154. http://dx.doi.org/10.1007/s11229-013-0252-x 